\title{
A RAZÃO E A LOUCURA: ANÁLISE SEMIÓTICA E ANTROPOLÓGICA DO CONTO O ALIENISTA DE MACHADO DE ASSIS
}

\author{
Karylleila dos Santos Andrade (UFT) \\ karylleila@gmail.com
}

\author{
ASSIS, Machado. O Alienista. \\ São Paulo: Abril Educação, 1980.
}

O ALIENISTA é um conto de Machado de Assis dividido em 13 capítulos. Publicado em 1882, no livro Papéis Avulsos, narra a estória de Simão Bacamarte, médico interessado em conhecer as fronteiras entre a razão e a loucura. Com esse objetivo se instala em Itaguaí, localizado na região Fluminense, onde é recebido com todas as honras pela comunidade local. Mas a aprovação cessa quando Simão recolhe na Casa Verde pessoas cuja loucura a população não compartilhava. $\mathrm{O}$ barbeiro Porfírio lidera uma revolta popular contra a ciência do alienista. A rebelião é sufocada, mas Simão Bacamarte continua multiplicando suas internações.

$\mathrm{Na}$ tentativa de estabelecer os limites entre a razão e a loucura, o médico interna, numa primeira etapa, todos os indivíduos que manifestam hábitos ou atitudes que, embora discutíveis, são toleradas pela sociedade: os politicamente volúveis; os sem opinião própria, os mentirosos, os que vivem fazendo discursos ou versos empolados, os vaidosos, entre outros.

Para a satisfação da população de Itaguaí, o alienista, de repente, solta todos os recolhidos na Casa Verde e adota critérios inversos aos anteriores a fim de caracterizar a loucura: os loucos, agora, são os leais, os justos, os honestos, os imparciais. A terapêutica de Simão, para esse tipo de loucura, consiste em eliminar as "virtudes" de seus pacientes, o que consegue com certa facilidade, declarando-os em perfeita sanidade. A partir disso se reconhece como o único louco irremediável. Isola-se na Casa Verde, onde morre dezessete meses depois. 
Machado de Assis trata da ironia a partir do plano políticosócio-moral, fazendo da mesma uma técnica narrativa constante: sua estrutura fabular preferida apresenta a frustração de uma expectativa, pois os acontecimentos tomam um rumo contrário ao esperado, surpreendendo continuamente as conjecturas do leitor. A essa forma irônica está ligado, indissoluvelmente, um conteúdo humorístico, porque, como sabemos, a essência do cômico reside no desvio da normalidade. Dentre os inúmeros contos que abordam essa concepção irônica machadiana do destino como frustrador das expectativas humanas, destacaremos $O$ ALIENISTA.

Ironicamente esse conto machadiano expressa em forma de arte a tese de que o homem verdadeiramente lúcido é um louco, porque é anormal. A lucidez mental é sintoma de loucura, pois faz com que o homem, na tentativa de ser autêntico e coerente com os postulados ideológicos, se isole da maioria que vive segundo a opinião, o parecer.

Autor da época realista-naturalista, Machado de Assis dialoga ora de forma implícita ora de forma explícita com situações e discussões da época: o positivismo de Comte, o darwinismo biológico e social, o evolucionismo de Spencer, como também as ideias liberais vigentes nos fins do século XIX no Brasil.

Quanto às características estéticas, vistas sob um contraste do Romantismo e o Realismo-Naturalismo, a realidade apresentada em O ALIENISTA é uma visão ainda matizada da sociedade da época, embora se apresente de forma menos camuflada, como foi apresentada no Romantismo. O amor agora é vencido pela natureza. Como exemplo, temos D. Evarista, esposa de Simão Bacamarte, que é escolhida porque reunia condições fisiológicas e anatômicas de primeira ordem. Poderia, assim, gerar filhos "robustos, são e inteligentes". Em foco o determinismo biológico: discussão da filosofia da época.

O conto, O ALIENISTA, foi escrito na época em que se começava a falar do evolucionismo e teorias deterministas no Brasil. Surgiram adeptos entusiastas da teoria spenceriana, como Silvio Romero. Cético, Machado de Assis pretende explicar de maneira mecânica e positiva o mistério do universo. Daí os contos Evolução e $O A L I E$ NISTA, os quais encerram uma dupla sátira: filosófica e política. 
Ele interpreta o evolucionismo como uma crítica, pois aceitar esse tipo de teoria implicava analisar a evolução brasileira sob as luzes das interpretações de uma história natural da humanidade. O estágio civilizatório brasileiro se encontrava definido como "inferior" em relação à etapa alcançada pela Europa. $\mathrm{O}$ autor conhece a distância entre teoria e realidade, o que se consubstancia na construção de uma identidade nacional. É preciso apresentar a realidade nacional com contornos e peculiaridades pertinente ao caráter nacional. Simão Bacamarte, no ímpeto de compreender os males na sociedade de Itaguaí, procura por meio da ciência interpretá-los e descobrir as causas, remédios e a cura universal: a loucura é compreendida como um mal à sociedade. É preciso curá-la. Para compreender a sociedade humana, é necessário completar com outros argumentos que possibilitem o entendimento da especificidade social.

É importante salientar aqui as ideias de Nina Rodrigues citado por Ortis $(1985$, p. 20) no que se refere à ideologia de supremacia racial: as raças superiores se diferenciam das inferiores e, que no contato inter-racial e na concorrência social, vence a raça superior. Fazendo um paralelo com as experiências de Simão Bacamarte, vimos que, no primeiro momento, a necessidade de separar os "mansos" dos "loucos". Estes podem prejudicar o andamento do progresso civilizatório da sociedade de Itaguaí. Por sua vez, aqueles, considerados os "equilibrados", estão socialmente aptos a promover o desenvolvimento.

Ainda com o enfoque nas teorias da época, é mister apresentar a relação do evolucionismo e os organismos biológicos de Manuel Bonfim citado por Ortis (1985, p. 23). Bonfim afirma que as sociedades existem como organismos similares aos biológicos; e a análise da nacionalidade depende do meio em ação combinada com o seu passado. Da analogia entre biologia e sociedade chega-se à noção de doença. $\mathrm{O}$ autor define doença como uma inadaptação do organismo a certas condições especiais.

Em O ALIENISTA, encerram-se vários tipos brasileiros, genuinamente brasileiros, no pensamento atribuído por Romero (1960): D. Evarista, o barbeiro, o Padre Lopes. O autor conseguiu explorar, nessas personagens, verdadeiras características sociais, contemplan- 
dos-as a partir da psique humana, resultando tipos humanos brasileiros, contrariando as formas e moldes estéticos do Romantismo.

A intertextualidade está presente durante o percurso gerativo do texto. $\mathrm{O}$ autor refere-se aos diálogos intertextuais de forma metafórica: "Bastilha da razão humana", caracteriza-se aqui uma críticasatírica aos acontecimentos europeus, própria da linguagem irônica machadiana; analogia de Simão Bacamarte a Hipócrates, considerado o Pai da Medicina, e Catão, filósofo austero e moralista. Há também referências ao Positivismo, quando o barbeiro, num discurso eloquente à multidão, recomenda a ordem. Ou seja, a presença da assimilação da retórica do progresso e da igualdade e liberdade, pois essa é a base do governo dele. Percebe-se também a adoção de ideais liberais e a luta pela República: a luta da população pela liberdade em Itaguaí. O dilema da burguesia é evidenciado e caracterizado por algumas personagens, entre elas, o boticário, D. Evarista e o barbeiro.

Numa leitura semiótica, pode-se analisar o percurso do sujeito Simão Bacamarte, O alienista, de forma querer-poder-fazer. Durante o percurso gerativo de sentido, esse sujeito cumpre então vários papéis: sujeito do querer-ser e do querer-fazer - "A ciência, disse ele a Sua Majestade, é o meu emprego único (...)”; do sujeito quererpoder, sujeito realizado pelo fazer e pela obtenção dos valores desejados - "O principal nessa minha obra é estudar a loucura (...) descobrir enfim a causa do fenômeno e o remédio universal."

Simão Bacamarte, no percurso narrativo do destinador-manipulador, propõe, nos vários papéis desempenhados, um contrato e exerce o poder de persuasão para convencer o destinatário a aceitálo. Durante o percurso do fazer-persuasivo de $O$ ALIENISTA ou fazer-crer, ele apresenta uma tipologia simples de manipulação: tentação, sedução, provocação e intimidação. No primeiro, a tentação é revelada quando ele solicita à Câmara licença para agasalhar e tratar os loucos de Itaguaí e vizinhança; depois vem a sedução, no momento em que ele afirma descobrir a causa do fenômeno da loucura e o remédio para curá-la; logo em seguida, a provocação e intimidação, quando ele chega à conclusão de que a razão é o perfeito equilíbrio de todas as faculdades, fora daí insanidade. Solta todos os internos e se reclusa na Casa Verde, reconhecendo que ele próprio é o único 
louco na cidade. A ordem na manipulação dependerá da relação entre manipulador e manipulado.

Pode-se concluir que este conto machadiano representa o início da conquista da literatura de autenticidade. Observa-se que o dilema dos intelectuais, sobretudo retratado aqui por Machado de Assis, era o de construir uma identidade nacional. Para tanto é necessário se reportar a condições reais da existência do país. Schwarz (1992), ao estudar a obra de Machado de Assis, se refere à dualidade desse escritor. Assinala a discussão que há entre o discurso ideológico da classe dirigente e a própria realidade social.

Da imitação ruim dos moldes europeus, caracterizados no período anterior, para uma revolução nos moldes estéticos de ver de forma mais coesa e nacionalizada a sociedade político-cultural brasileira do século XIX. Enfim, ver-se nos costumes, na moda, nos símbolos nacionais, nos pronunciamentos de revolução, no ideal liberal, nas discussões teóricas vigentes, nos tipos humanos brasileiros, porém sem desvalorizar o pensamento europeu. Schwarz (1992) propõe, nesse conto, a ideologia de independência cultural ainda que de forma precursora. Percebe-se que Machado de Assis, ironicamente, já insiste nessa busca da identidade cultural brasileira, fomentado, na época, por meio da busca dessa autonomia, um suicídio cultural quando Simão Bacamarte se interna, se isola. O suicídio é a negação de si e do outro: Simão Bacamarte isola-se, por isso morre.

\section{REFERÊNCIAS BIBLIOGRÁFICAS}

ASSIS, Machado. Seleção de textos, notas, estudos biográficos, históricos e crítico. São Paulo: Abril Educação, 1980.

BARROS, D. L. Pessoa de. Teoria do discurso: fundamentos semióticos. São Paulo: Edusp/Humanitas, 2001.

BROCA, Brito. Machado de Assis e a política. São Paulo: Polis, 1983.

CÂNDIDO, Antônio. Radicalismos. Estudos Avançados. USP, set/1988. 


\section{FACULDADE de FoRMAÇÃO de PROFESSORES}

GLEDSON, John. Machado de Assis: contos/uma antologia. São Paulo: Cia. das Letras, 1992.

ORTIS, R. Cultura brasileira e identidade nacional. São Paulo: Brasiliense, 1985.

ROMERO, Silvio. História da literatura brasileira. Rio de Janeiro: José Olympio, 1960.

SCHWARZ, Roberto. Ao vencedor as batatas. São Paulo: Livraria Duas Cidades, 1992. 